\title{
Health technology assessment in Denmark: Strategy, implementation, and developments
}

\author{
Helga Sigmund \\ National Board of Health, DACEHTA \\ Finn Børlum Kristensen \\ University of Southern Denmark and National Board of Health, DACEHTA
}

\begin{abstract}
Objectives: The mainly tax-paid healthcare system in Denmark is decentralized with three defined policy and management levels. Health technology assessment (HTA) as a concept was introduced in the beginning of the 1980s. Significant implementation only happened when the first national strategy for HTA was developed by relevant stakeholders and issued as an official document in 1996. The introduction and the further development are described.

Methods: The Danish Institute for HTA was established in the National Board of Health in 1997 with responsibility for coordination and production of HTA. A local government reform from 2007 provides several new challenges to HTA and its coordination.

Results: An external evaluation in 2003 indicated that HTA was widely disseminated and that HTA results were benefitting political, administrative, and clinical decision making at all levels of the healthcare system.

Conclusions: The first national strategy for HTA, the broad HTA model covering four elements: Technology (clinical aspects), Patient, Organization, and Economy, and the development and introduction of mini-HTA as a tool for HTA-related activities in institutions and municipalities are major contributions to international HTA.
\end{abstract}

Keywords: Health technology assessment, Denmark, Health policy, Strategy

\section{THE HEALTHCARE SYSTEM}

Denmark is a small and wealthy Scandinavian country with approximately 5.5 million inhabitants. It has been a member of the European Union (EU) since 1973. Denmark is a constitutional monarchy with an elected parliament. The Ministry of Health and Prevention is, together with twenty other ministries, part of the central administration. The National Board of Health is the key ministry agency with a defined independent role in relation to health matters (11).

\section{Decentralized Structure}

The Danish healthcare sector is characterized by decentralization. There are three political and administrative levels: the national level (the state), regional level (counties/regions), and local level (municipalities). For several decades, the country was divided in fifteen counties and 271 municipalities. However, a local government reform in January 2007 generated fewer and larger entities, consisting of five regions and ninety-eight municipalities, and caused many changes in distributing tasks and responsibilities.

The state is in charge of providing the legal and economic framework and the overall goals for health care, as well as initiating, coordinating, and supervising the regional and municipal delivery of health services. The Ministry of Health and Prevention is, as the formal authority, responsible for legislation, including legislation on health provision, personnel, hospitals, pharmacies, medical products, vaccinations, pregnancy health care, child health care, and patients' rights. The National Board of Health develops guidelines 
and supports efforts for improving quality, productivity, and efficiency in health care (11).

The healthcare system consists of two large sectors: primary health care and the hospital sector, also called the secondary sector. The five regions are responsible for delivering service in both sectors. In primary health care, almost all services provided by practicing self-employed doctors are paid by the regions. Furthermore, the regions own and operate most of the hospitals. Thus, hospital doctors are employees of the regions (18).

One of the goals of the local government reform in 2007 was to strengthen the role of the municipality in prevention, health promotion, and rehabilitation. The ninety-eight municipalities are responsible for home nursing, public health care, school health service, child and dental treatment, prevention, and rehabilitation. Centralization of the delivery of hospital services was another goal of the reform $(11 ; 18)$.

\section{Financing and Regulations}

Denmark is characterized by a strong tradition in terms of welfare and democracy. Thus, health care is considered a public responsibility. Important cornerstones of the healthcare system are (i) free and equal access to health services; (ii) financing through taxation, public management (decentralized); and (iii) freedom of choice.

The Danish healthcare system was developed on the principle of universal, free, and equal access. The health services are mainly financed through taxation (local and state), and the vast majority of health services are free of charge for the users. However, user payment is to a certain degree assigned to dentistry, physiotherapy, and pharmaceuticals, and complementary private insurance is increasing.

Health care in the regions is primarily financed by a block grant from the state (75 percent). The additional financing ( 25 percent) comes from a state-related subsidy, a local basic contribution, and a local activity-related contribution. In 2005, health expenditure constituted 9.4 percent of the gross national product (GDP), which placed Denmark above the Organisation of Economic Co-operation and Development average and other Nordic countries. The same year, the public share constituted 84 percent of the total health expenditure, while 16 percent was private health expenditure (11).

Primary Health Care. The general practitioner (GP) (primary care physician) is the primary contact with a coordinating function and is responsible for ensuring that the correct treatment is given by the correct professionals by referring patients to hospitals, specialists, and other health professionals. Thus, the Danish system is organized on the basis of GPs having a "gatekeeper" function with regard to the rest of the primary health services and the hospital services. GPs and other practicing health professionals in primary health care are administrated and reimbursed by the regions, mainly by means of a fee-for-service system (18).
Hospital Services. Both somatic and psychiatric health care is carried out by public hospitals, which are administrated by the regions. The framework for how a region's hospital service should be provided is given in a plan covering the activities of the regional healthcare system. Guidance and regulations with regard to different forms of treatments in hospitals are given by the National Board of Health as a contribution to healthcare planning (11).

Concerns mainly with waiting times led to the introduction of patients' free choice of hospital in 1993. A more recent initiative to "extended free choice" was taken in 2007 , consisting of the introduction of a 1-month general waiting time guarantee and guaranteed initiation of hospital specialist care within 48 hours in case of cancer diagnosis and certain heart diseases (18). As seen in other European countries, the number of hospitals has decreased and this development is expected to continue over the coming years.

Prevention. Lifestyle-related diseases were more and more in focus through the most recent decade. Since the local government reform in 2007, the primary responsibility for providing primary health care is given to the municipalities, rather than the state or the regions, taking into account the closer contact between the local authorities and citizens (11).

\section{Technologies}

There is no central control of the uptake of technologies, such as new methods, treatments, devices, and pharmaceuticals in health care. The National Board of Health advises on which services are reimbursed by the public health insurance scheme, and, when requested, on the introduction of technologies in hospital care. Drugs are licensed by the Danish Medicines Agency. The Agency is also responsible for licensing medical devices according to the EU regulations (18).

\section{EVALUATION AND ASSESSMENT}

\section{Introduction of Health Technology Assessment}

In Denmark, health technology assessment (HTA) has been under development as a concept in the political health debate since the beginning of the 1980s. HTA was officially introduced in the form of a report, a so-called White Paper. The study was produced for the Committee for Scientific Research of the Danish parliament, authored by Dr. Per Buch Andreasen, later President of International Society of Technology Assessment in Health Care (ISTAHC) (1). At approximately the same time, the first Danish HTA report was published by Danish Institute for Health Services Research (DSI) (7). DSI kept on with HTA activities $(5 ; 14)$ until now and participated in several international activities.

In 1982, the actual responsibility for HTA was assigned to the National Board of Health. In 1984, the first version of an Introduction to HTA Methodology was published by the Board (revised twice, in 1994 and 2000) (17;19;21). A few 
years later, in 1986, the introduction was followed up by a model project for HTA dealing with ultrasound screening in pregnant women (20). However, no specific resources were allocated to the field of HTA at that time, and the role of HTA remained underdeveloped for almost a decade.

\section{Early Developments}

After an early promising start, an expected progress of HTA failed to materialize. There were, nevertheless, a whole series of HTA activities during the course of the 1980s, such as the development of methods, teaching, specific HTA studies and spreading of information. These provided experiences that later proved to be of value for HTA development. The initiatives were, however, sporadic and characterized by a lack of resources. This lack of central support almost brought HTA development in Denmark to a standstill during 198791, precisely at a time when countries such as Sweden, the Netherlands, and France were beginning to establish national and regional HTA institutions and HTA programs $(8 ; 15)$.

In Denmark, terminology such as "quality assurance" and "clinical guidelines" attracted attention, whereas HTA languished as a subcategory of an overall national quality concept until approximately 1994.

In the mid-1990s, additional ways of renewing and increasing the effectiveness of the health service were sought by the state. The future promised a stream of new knowledge and technological innovations. This applied to drugs and medical devices, as well as diagnostic methods, therapies, nursing, preventive care, and rehabilitation, that is, areas that fall under the general definition of "health technology." Misplaced investment was to be avoided, and the new buzz words were "value for money," "priority-setting," and "evidencebased health care." The demand for better informed decision processes took over. HTA was rediscovered and was to adapt to the new challenge (15).

Some neighboring countries were some steps ahead. In these countries, HTA had assumed a recognized position as a tool for supporting decision making concerning the application of health technologies. This time the Danes acted quickly.

In relation to a report on the hospital sector's economy, in 1994 there was a shift of focus that gave the basis for further development of HTA. It was proposed to establish a new independent HTA committee with broad representation of stakeholders under the National Board of Health, and the counties were recommended to give higher priority to HTA. These initiatives came up from intentions to improve the evidence of clinical effectiveness and to ensure optimal use of resources and ethical acceptance. Thus, HTA became increasingly salient in Denmark.

In 1995, the HTA committee was commissioned to develop a national HTA strategy within a short period of time. Earlier experience was examined and new international experience was drawn upon. The strategy was ready in 1996 (22) and was the first of its kind in the world.
The Danish national strategy for HTA promoted seven points: (i) incorporation of HTA in planning and policy processes at all levels of the health service, (ii) criteria for priority setting of HTA topics and selection of areas for intervention, (iii) utilization of results of foreign and international HTAs, (iv) identification of research needs to further development of methodology, (v) overall coordination of further development in the field of HTA, (vi) consolidation of the strategy with necessary financial resources, and (vii) regular evaluation and adjustment of the strategy.

The first strategy point has definitely been the most important component for a country with a decentralized healthcare system. The incorporation of HTA is aimed at a broad range of decision processes at central, decentralized, and institutional levels, at political as well as at administrative bodies, in clinical work as well as in research and in relation to associated industries. This concerned a necessary widespread change of attitudes throughout the health service and influenced to a great extent the way HTA was developed in Denmark. It is also the strategy point by which Denmark essentially differs from other HTA-active countries (15).

Another significant point of difference, particularly in relation to non-Scandinavian countries, lies in the breadth of the Danish HTA concept. The concept is based essentially on the definition of the EUR-ASSESS Project and the definition developed by the International Association of HTA Agencies (INAHTA) $(6 ; 16)$. The domains of "organization" and "patient aspects" are explicitly indicated as priority areas of analysis. When tackling individual HTA projects, a broad approach should be attempted, allowing analyses of alternatives to the technology in question to be included $(9 ; 10)$. Further essential points of the HTA concept are policy-orientated questions and systematic interdisciplinary analyses and synthesizing processes that are firmly based on research and scientific methods (15).

HTA results are, according to the tradition that has developed in Denmark, contributions (input) to subsequent decision-making processes, and are not decisions in themselves. HTA results can aid decisions in various fields, for example, by helping politicians to set priorities, administrators to plan and manage, clinicians to integrate new knowledge, and patients to choose between different treatment options (15).

\section{Institutionalization}

In 1997, HTA became part of the research strategy for the Danish Medical Research Council. At this time, sufficient political momentum was present in the Parliament for founding a national HTA Institute, financed by state funding allocated from the Budget. Different organizational models were discussed, reaching from an independent institution totally on its own to an institutional allocation. Due to the earlier affiliation and relations in terms of tasks, the institute was placed under the National Board of Health which is the 
Ministry of Health's main agency. The main task of the new HTA Institute (which later became DACEHTA) was the implementation of the national HTA strategy.

Two Advisory Boards supported DACEHTA from the outset: (i) the Scientific Advisory Board, consisting of 10 researchers in fields relevant to HTA (e.g., statistics, economies, organization, patient aspects, epidemiology, and different branches of medicine), which is still in place; and (ii) the Strategic Advisory Board, with approximately twenty stakeholder representatives (e.g., academic institutions, health administrations, specialist organizations, and industry).

In its first 9 years, DACEHTA was a separate entry in the state budget. The most important tasks of the institution were promoting and furthering HTA, initiating and supporting HTA projects, including collaboration with the health services and its relevant research and educational bodies. DACEHTA saw and still sees itself as the intermediary between research and the health service, and as provider of systematically developed input to decision making. Concerning projects, DACEHTA carried out its own comprehensive HTA studies at a national level, and annually called and granted several projects that were initiated externally, that is, by regionally or locally based groups, hospitals, or other relevant institutions (15).

In April 2001, as a result of a parliamentary act, the HTA Institute was merged with the approximately similarsized "Danish Hospital Evaluation Centre." The new institution was called the "Danish Centre for Evaluation and HTA" (DACEHTA). In the first year, DACEHTA had an annual budget of 50 million DKK (approximately 6.7 million euro)the largest budget it ever had. The reasons that were given for the merger were of both practical and methodological character-not least with a view to achieving potential synergy effects.

A further development, that is, to improve the mediation of HTA results, was the creation of a secretariat for Clinical Practice Guidelines under the Danish College of Physicians with financial support from DACETHA in 2000. In 2004, the secretariat became an integrated part of DACEHTA. Additionally, a small unit that was specialized in working with evidence-based prevention projects became part of DACEHTA.

The phase of merging and expansion in the early 2000 s was followed by a phase of separation, organizational integration into the National Board of Health, and a single merger. In 2005, the secretariat for guidelines was moved to another department, and closed in 2007. At the same time, the tasks concerning prevention and evaluation were allocated to other parts of the National Board of Health.

These changes made room for a focus on HTA and DACEHTA's growing HTA activities at the international level, primarily the hosting of the secretariat of the EUnetHTA project. Furthermore, by disseminating HTA knowledge throughout other parts of the Board, the conversions supported the aim to improve evidence-based approaches in general at the National Board of Health. Finally, in 2008, the HTA activities were merged with monitoring and evaluation activities into a larger administrative unit, within which DACEHTA is one of the functions.

Thus, the conditions and the organizational settings concerning DACEHTA have been changing over time. The agency has moved from financial independence and a high degree of organizational independence in the late 1990s to becoming an integrated part of the National Board of Health in every way. The process of integration was accelerated in recent years. The definitive integration occurred along with a general empowerment of the National Board of Health as part of the local government reform in 2007.

Along with the organizational changes, the coordinating role of DACEHTA at the national level became increasingly important. This led, in 2008, to the establishment of a Danish HTA-producer network consisting of HTA units and groups in regions, university hospitals, and research institutes.

\section{Early Attempts, Successful Steps, Survival}

In addition to carrying out its own HTA projects at the national level, DACEHTA focused on setting up a national HTA network. This was done by (a) teaching activities, in for example, hospitals, universities, and so on; (b) establishing of three regional HTA units together with counties and universities; and (c) funding of HTA projects that were external initiated and supported by a granting mechanism.

Finances for project grants were a specific part of DACETHA's budget. Interested parties could apply with project descriptions. There was a great interest, and only a small percentage was granted funding. The view of the Scientific Advisory Board played an important role in assessment of the proposals before granting. In the period from 1997 to 2006, approximately 135 HTA projects were funded-the majority of them totally, the rest cofinanced.

By January 2007, along with the local government reform and the final integration of DACEHTA's budget into the budget of the National Board of Health, external granting was closed down. Regardless of the local government reform, the role of coordinating HTA in Denmark rests unchanged at the state level. However, the economic conditions have changed. The regions, municipalities, and other sources are expected to take over the responsibility and/or the financial support for the decentralized HTA activities, including regional and local units.

The priority given to having a common national strategy for HTA was confirmed in 2008 when the stakeholders in the newly established Strategic Council for HTA, which replaced DACEHTA's Advisory Board, decided to revise the 1996 strategy. A draft went for public consultation, and by the end of 2008, the Minister of Health and Prevention signed the preface of the new strategy. The strategy confirms and updates much of the original strategy, and has a strong 
emphasis on national coordination and concrete implementation at regional and municipality level. International involvement and ensuring a strong research basis for HTA is confirmed as cornerstones for Danish HTA.

\section{Development of Expertise, Training, and Education}

HTA Handbook and HTA Courses. In 2001, a first version of an HTA Handbook was published, covering the main elements of the Danish HTA concept (9). The book became widely known and used by doers and users throughout the Danish healthcare system, and was used as a basis for several summer schools and basic HTA courses for HTA-project participants.

The maturing experience with doing HTA, new types of HTA, and the new structure in the Danish healthcare system, called for a thorough revision of the Handbook. Thus, a new Handbook was released by DACEHTA in the beginning of 2008 (10). The aim of the Handbook was to support and qualify the decentralized activities and, in an English translation, to contribute to international education and methodologydevelopment-in congruence with the work of EUnetHTA (4).

The new HTA Handbook is (a) bringing into focus and providing tools for maximal use of relevant existing studies and information, along with only the most indispensable collection of primary data; (b) introducing methods more related to the process of doing an HTA; and (c) providing updated research-based methods for the analytical elements, especially concerning two of the least developed subjects, that is, organizational and patient-related aspects.

Educations Involving HTA Approaches. HTA classes are available at several universities in relation to fields such as public health, social pharmacy, and medical engineering. In addition to this, HTA is included in some medium-term educations, for example, schools for medical technologists and physiotherapists. Currently, HTA is only introduced as a concept to medical students, but HTA has become part of the common elements of specialist education for all medical doctors.

\section{Growth in Influence and Credibility: External Evaluation}

The origin national strategy included a demand for evaluation of DACEHTA and its activities. In 2003, approximately 5 years after the establishment of DACEHTA, an external evaluation was initiated on the request of the National Board of Health. The evaluation was carried out by a group of four Nordic evaluators, three university professors, and a top healthcare manager with a strong background in clinical research.

As a basis for the Nordic evaluation committee work, several background analyses had been performed in advance by a Danish consulting agency, covering surveys among HTA investigators and users of HTA results, involving county health administrators and hospital managers. Furthermore, interviews with regional HTA organizations and relevant units of the National Board of Health were carried out.

The evaluation by the Nordic committee included focusgroup interviews with important stakeholders, representing associations of healthcare providers, patient associations, research and industry, as well as members of DACEHTA's two Advisory Boards.

It was concluded that the diffusion of HTA knowledge and dissemination of HTA reports throughout all levels of the healthcare system (addressing both HTA doers and users) was successful in terms of use of HTA results, national and international networking, initiation of new projects, and educational activities. Users and stakeholders had great confidence in the validity of the HTA reports, and it was clearly indicated that the input of HTA results was benefiting political, administrative, and clinical decision making on all levels in health care.

However, several areas that needed further development were also identified. The most important ones were (i) strategies for more active implementation of results, (ii) decrease in duration of HTA processes, (iii) improved procedures for choice of HTA topics, and (iv) improvement of the use of international knowledge, for example, joint activities.

During the latest years, DACEHTA has made efforts for improving the areas as requested in the evaluation report: (i) Implementation of HTA results may be improved by (a) the fact that DACEHTA has become an integrated part of the National Board of Health and (b) much closer contact and information exchange with stakeholders and potential users. (ii) Decrease in duration of HTA processes has been achieved by (a) developing new HTA products with shorter production times (mainly by focusing the policy question), but still considering the broad approach of Danish HTA; (b) improving the use of existing knowledge by using foreign HTA products primarily in Nordic languages and English, and presenting them with additional information concerning Danish health care and expert comments; and (c) performing joint HTA activities together with other countries, for example, by way of Core HTAs. Core HTAs may also answer the specific request for common international HTA production. (iii) Processes for choice of topics have been systematized and further developed in relation to the work of the new Strategic Council for HTA.

\section{CURRENT SITUATION}

\section{Types of HTA Products}

Danish HTA products are distributed on three main categories:

(1) HTA reports. Most reports address a well-defined problem and, for example, focus on a single technology. The time frame is a 
maximum of 1 year, and the peer-reviewed report is approximately 100 pages. Special HTA reports are produced on selected cancer drugs at the request of the National Board of Health.

(2) HTA Products Integrating Foreign Work. There are two types: "foreign HTA with comments" and "core HTA" (where different parts of the HTA are carried out in different countries).

Foreign HTA with comments is based on a foreign HTA report that has comments mainly related to Danish conditions. The time frame is 3 to 6 months, and the report has a length of approximately twenty-five pages, consisting of a summary of the foreign HTA and comments from Danish experts.

Core HTA is based on a problem that is of current interest in several European countries. Core HTA, which is a product of EUnetHTA, is not a full HTA itself, but rather a pool of information and results that can be used for localized HTA reports in different countries. DACEHTA will explore the usefulness of Core HTA in the coming years.

(3) HTA-Related Products. These are mini-HTAs and "early warning" of new technology (including foreign early warning with comments).

Mini-HTA is based on a questionnaire framework containing twenty-six HTA questions (3) (www.dacehta.dk). It is an operational oriented tool and provides input for decisions at the local level, for example, hospitals, departments. MiniHTA concerns proposals for new treatments or changes, and reflects the four domains, "boxes", in Danish HTA: clinical evidence, organization, patient aspects, and economics. Mini-HTA is an increasingly obligatory input when hospitals consider or plan new provisions or acquisitions. All miniHTAs from hospitals are collected by the regions and entered into a common database to provide a national overview. A mini-HTA tool for municipalities is currently being piloted.

Early warning informs decision makers about future technologies that may be introduced. Foreign alerts will be the main information for this product.

In addition, external projects that received a grant from DACEHTA are published by DACEHTA in a separate series. All HTA reports undergo external peer review.

\section{International Cooperation}

DACETHA has been a partner in a series of international projects, for example, INNO-HTA (HTA-methodology for innovative healthcare technologies), ECHTA (European Collaboration for HTA), HTA Europe, ASTEC (Analysis of Scientific and Technical Evaluation of Health Interventions in the European Union), and AGREE Collaboration (Assessment of Guidelines Research and Evaluation). This was followed up by DACEHTA taking the lead in the project European Network for HTA (EUnetHTA). EUnetHTA was a 3-year project with the aim of establishing a formal European HTA network. EUnetHTA was initiated by the EU Commission on the request of the Council of Ministers in EU and was launched in 2006 with its Secretariat in DACEHTA.
The project comprised twenty-seven European countries of which twenty-four countries were members of the EU. Practically oriented from conception, EUnetHTA was intended to ensure a more efficient utilization of the resources that are used for the assessment of health technologies, and to enhance the quality and validity of decisions on the application of technologies. These objectives were achieved through increased coordination, division of labor and knowledge-sharing at a European level. Models and method development aimed at using common knowledge and reducing duplication in relation to specific HTA projects. The work of EUnetHTA was structured in eight "work packages," each of which involved many participant countries. The network will grow into a permanent EUnetHTA collaboration from 2009 ensured by twenty-five founding partners (www.eunethta.eu/Contact/Founding_Patners/)).

Furthermore, DACEHTA has particular close links to the Nordic sister-institutions in Sweden, Norway and Finland, and is still an active member of the international networks HTAi, INAHTA, and EuroScan.

\section{DISCUSSION}

The very explicit emphasis on the broad scope of HTA, which is reflected in the INAHTA definition and the "four boxes" in Danish HTA, has had an effect on reports. When compared with reports from INAHTA member agencies, reports from Denmark have a broad scope (2). When eleven HTA institutions were scored on the basis of degree of extensiveness of their reports (in terms of presence of content on clinical, economic, patient, and organizational aspects) $(\mathrm{N}=433)$, the DACEHTA reports scored highest $(11.9 ; \mathrm{n}=17)$ ), with SBU, Sweden $(9.9 ; \mathrm{n}=39)$ and Health Council, the Netherlands $(7.0 ; n=19)$ and SMM, Norway $(7.0 ; n=22)$ coming next.

Economic evaluation is an integral part of HTA, and dependent on the results of the review of clinical effects and organizational analysis. Thus, the economic evaluation is often postponed until those results are available. The estimation of, say, an incremental cost-effectiveness ratio is one important result of the HTA. Nevertheless, the economic evaluation is integrated into the synthesis of all assessment elements and is not the end result of the HTA, and there is no defined "threshold" in Denmark.

Having a national strategy for HTA developed with stakeholders and endorsed by the Minister of Health at the outset has proven decisive for the broad adoption of HTA at all levels in Danish health care, which is very decentralized when compared with many other countries. The implementation of the strategic aim was reflected in the work plans of DACEHTA from start, and during the first 10 years, it was possible to support local HTA projects through grants. Common development of instruments such as standard layout of HTA reports, the HTA Handbook, and the mini-HTA tool has kept HTA producers together in Denmark. 
The funding of HTA projects in the five new regions and the municipalities was not in place when implementation of the healthcare reform was started in 2007. The HTA capacity that was developed until 2005 is dependant on resources. The regions are obliged to ensure research including health services research. However, the law on Health Services does not explicitly mention HTA.

The Danish report on human papilloma virus (HPV) vaccination (13) to reduce the incidence of cervical cancer is a particularly good example of a successful interaction between planning and HTA - and of international collaboration. When vaccines were entering the market, it was decided to do an HTA. The alert came from the clinical world, which saw the public health perspectives, and the challenges. The Danish Medicines Agency did not allow reimbursement of any cost of the vaccines. There was a lot of lobbying and pressure on the Parliament to make a political decision, but the Minister of Health wanted to wait for the results of the HTA, and the recommendations from the National Board of Health. The report was published in May 2007, the recommendation was send to the Minister in October, and the Parliament put the funding of vaccination of all 12-year-old girls as part of the general vaccination program on the Budget for 2008 and onward.

Collaboration with EUnetHTA Partner agencies on HPV vaccination was initiated by DACEHTA in October 2006, and this led to the sharing of literature search protocols, economic models, draft reports, and information on policy processes between organizations in Austria, Belgium, Denmark, Finland, Ireland, Italy, Netherlands, Norway, and Sweden. Those involved experienced the added value of EUnetHTA for sharing information on a specific technology that decision makers had in front of them across Europe, and where HTA was urgently needed.

The timing of HTA in relation to decision making and planning is crucial, and the necessary immediate solution has been the focused HTAs, commented foreign HTAs, and mini-HTA. Horizon scanning and alerting and a system to capture the right topics for HTA can facilitate that there will be sufficient time to do high-quality HTA work. The new Strategic Council for HTA is involved in a system that will capture the topics for HTA and the Council will advise on their prioritization. Hopefully, this will become a system where there is an early identification of highly relevant topics for HTA and a link to the planning and decision processes in the health sector, so that timing is right and there is time to do high-quality HTAs.

The emphasis in Denmark on broad scope of HTA and on addressing all types of technologies (such as in current HTA projects on patient education in chronic diseases, ambulatory check-ups after cancer therapy, and early multidisciplinary intervention in patient with back pain) is a challenge to the HTA producers. On the one hand, this may increase the relevance of HTA for complex policy questions such as how to best handle care for patients with chronic dis- ease. On the other hand, the task is much more complex that doing a systematic review on efficacy and effectiveness and economic evaluation of a drug, which in itself is not a small task. Such projects also bring new research-based skills into the group of HTA producers, and this may increase the relevance of the HTAs for real-life planning and implementation.

In the long-run, there is a risk that HTA may miss the big picture by focusing on single technologies and their immediate comparators. Time and resources should sometimes allow time to do the broader HTAs such as the report on Diabetes Type 2 (12) — that means starting with a health problem rather than a technology.

\section{CONCLUSION}

When summarizing what has been unique in the development of HTA in Denmark and still characterizes Danish HTA, three issues should be highlighted: (i) The National Strategy claiming a broad approach to HTA to support decision making at all levels of the healthcare system; (ii) the broad HTA model covering four elements: technology (clinical aspects), patient, organization, and economy; and (iii) the development and introduction of mini-HTA as a tool for HTA-related activities in institutions and municipalities.

\section{CONTACT INFORMATION}

Helga Sigmund, MSc (hsi@sst.dk), Health Technology Assessment Advisor, DACEHTA, National Board of Health, 67 Islands Brygge, Copenhagen S, Denmark 2300

Finn Boerlum Kristensen, MD, PhD (fbk@sst.dk), Adjunct Professor, Faculty of Health Sciences, University of Southern Denmark, Winsløwparken 19, 3, Odense C, Denmark 5000; Director, DACEHTA, National Board of Health, 67 Islands Brygge, Copenhagen S, Denmark 2300

\section{REFERENCES}

1. Andreasen PB. Medicinsk teknologivurdering. Nyttiggфrelse af lagevidenskabelige forskningsresultater $i$ sundhedsvasenet. Rapport til Folketingets udvalg angående videnskabelig forskning. Afgivet 9. april 1980. København; 1980.

2. Draborg E, Gyrd-Hansen D, Poulsen PB, Horder M. International comparison of the definition and practical application of health technology assessment. Int J Technol Assess Health Care. 2005;21:89-95.

3. Ehlers L, Vestergaard M, Kidholm K, et al. Doing mini-health technology assessments in hospitals: A new concept of decision support in health care? Int J Technol Assess Health Care. 2006;22:295-301.

4. European network for Health Technology Assessment, EUnetHTA (www.eunethta.eu).

5. Hørder M, Jørgensen T, Nørrelund N. Teknologivalg $i$ den primare sundhedssektor. København: Dansk Sygehus Institut; 1988. 
6. International Association of HTA Agencies, INAHTA (www.inahta.org/HTA).

7. Jørgensen T. Teknologivurdering. København: Dansk Sygehus Institut; 1980. DSI-Specialrapport 80-107.

8. Jørgensen T, Kristensen FB. Medicinsk teknologivurdering i Europa. Ugeskr Laeger. 1998;160:2367-2370.

9. Kristensen FB, Hørder M, Poulsen PB, eds. Health technology assessment handbook. Copenhagen: Danish Institute for Health Technology Assessment, National Board of Health; 2001.

10. Kristensen FB, Sigmund H, eds. Health technology assessment handbook. Copenhagen: Danish Centre for Health Technology Assessment, National Board of Health; 2007.

11. Ministry of Health and Prevention. Health care in Denmark. Copenhagen: Ministry of Health and Prevention; 2008.

12. National Board of Health, Danish Centre for Evaluation and Health Technology Assessment. Type 2 diabetes. Health technology assessment of screening, diagnosis and treatment. Copenhagen: National Board of Health; 2005. Danish Health Technology Assessment; 2005:7.

13. National Board of Health, Danish Centre for Health Technology Assessment. Reduction in the risk of cervical cancer by vaccination against human papillomavirus $(H P V)-a$ health technology assessment. Copenhagen: National Board of Health; 2007. Health Technology Assessment 2007:9.
14. Sigmund H. Amalgam og dets alternativer — en medicinsk teknologivurdering. København: Dansk Sygehus Institut; 1991. DSI-rapport 91.01.

15. Sigmund H, Kristensen FB. Does health technology assessment benefit health services and politics? Eur J Health Econom. 2002;3:54-58.

16. Special Section: Report from the EUR-Assess Project. Int $J$ Technol Assess Health Care. 1997;13:133-333.

17. Statens Institut for Medicinsk Teknologivurdering. Medicinsk Teknologivurdering. Hvorfor? Hvad? Hvornår? Hvordan? København: Sundhedsstyrelsen; 2000.

18. Strandberg-Larsen M, Nielsen MB, Vallgårda S, Krasnik A, Vrangbæk K, Mossialos E. Denmark: Health system review. Health Systems in Transition. 2007;9:1-164.

19. Sundhedsstyrelsen. Medicinsk Teknologivurdering - hvad er det? København: Sundhedsstyrelsen; 1984.

20. Sundhedsstyrelsen. Model for medicinsk teknologivurdering. Ultralydsscreening af gravide kvinder. København: Sundhedsstyrelsen; 1986.

21. Sundhedsstyrelsen. Medicinsk Teknologivurdering. Hvad er det? København: Sundhedsstyrelsen; 1994.

22. The National Board of Health. The Health Technology Assessment Committee. National strategy for health technology assessment. Copenhagen: National Board of Health; 1996. 